\title{
Agricultural Co-Product Management: An LCA Perspective on the Use of Safflower Oilcake from Bio-Oil Production in Umbria Region, Italy
}

\author{
Simone PELARACCI ${ }^{1}$, Lucia ROCCHI ${ }^{2}$, Francesco ROMAGNOLI ${ }^{3}$, Antonio BOGGIA ${ }^{4}$, \\ Luisa PAOLOTTI ${ }^{5}$ \\ 1,2,4,5 Department of Agricultural, Food and Environmental Sciences, University of Perugia, \\ Borgo XX Giugno 74, 06121 Perugia, Italy \\ ${ }^{3}$ Institute of Energy Systems and Environment, Riga Technical University, \\ Azenes iela 12/1, Riga, LV-1048, Latvia
}

\begin{abstract}
This work evaluates the impact of cultivating Safflower (Carthamus tinctorius L.) in marginal lands of the Umbrian territory (Italy) to produce oil. The analysis considers the entire production process, aiming to understand which are the most impacting factors. In particular, the work assesses the environmental savings deriving from the reuse of the main by-product of the oil extraction process, i.e. the cake, for animal feed purposes. The evaluation was carried out by means of a cradle-to-gate LCA. The results show that the greatest impacts are due to the crop fertilization. However, such an impact is almost completely compensated by the use of the cake in feed production.
\end{abstract}

Keywords - Cascade cycle; environment assessment; life cycle assessment; safflower oil

\section{INTRODUCTION}

The concept of Circular Economy (CE) is inspired by the observation of non-linear and complex systems, in particular of regenerative, evolutionary living systems, capable of absorbing and enhancing the contributions of negative entropy available in nature [1]. The concept originates from a combination of founding disciplines such as Industrial Ecology, Regenerative Design, Natural Capitalism, Cradle to Cradle approach, and Blue Economy [1], [2].

The CE aim is to close the loop of materials, by reducing the resources consumption and the production of waste (i.e. emissions), by preventing any losses of substances, recovering them for reuse or recycling [3]. Regarding the agri-food sector, although some authors exclude the possibility of a completely circular food system, due to some intrinsic openness and complexity of it [3], it is possible to improve its global degree of circularity. In this context, a particular role is played by the valorization in food supply chains of plant-based by-products, which are very promising in some cases, while in others the sustainability and cost-efficiency at industrial scale have to be assessed [4].

The present study considers using a by-product, i.e. the oilcake deriving from seed oil extraction process, to produce feed. In particular, the authors considered safflower as suitable for cultivation in marginal soils due to its properties like being a rustic crop, resistant to

\footnotetext{
* Corresponding author.

E-mail address: francesco.romagnoli@rtu.lv
} 
drought, summer-long and long-day plant [5], [6]. These characteristics allow adhering to the philosophy of the reduction of inputs typical of the CE. The work focuses on assessing the environmental impacts of the production of safflower oil and the use of the associated cake for the production of feed through a Life Cycle Assessment.

\subsection{Safflower}

Safflower (Carthamus tinctorius L.) is an annual oil species belonging to the Asteraceae family (Compositae), originally grown for its flowers, which were used for dyeing fabrics and in food preparation, as alternative for saffron [7].

The ability of safflower to overcome different environmental stresses, such as extreme temperatures, drought, and salinity, has facilitated its expansion in the world areas characterized by both soil and climatic restrictions [5]. Today, safflower is primarily cultivated for its oil, as its linoleic and oleic fatty acids' content can have food and industrial purposes. Linoleic varieties contain about $70-80 \%$ of linoleic acid (polyunsaturated), making it an edible product to be used in salad oils and soft margarines. The oleic varieties contain about $80 \%$ of oleic acid (monounsaturated), and the oil serves as heat-stable cooking oil, or as a drying or semi-drying oil for paints and other surface coatings [8], [9]

Safflower seeds used for oil production may be either cold pressed, expeller pressed or solvent extracted [8]. The by-product, safflower oilcake, is mostly used as a protein component in animal feeding [5], [9]. The quality of safflower meal is highly variable as it depends on the quantity of hulls and on the extent of oil extraction. Dehulling improves crushing efficiency, but the hardness of the seed coat and the kernel's extreme softness make the operation costly and economically viable only if present a market for hulls [7], [8].

According to FAO data [10], in 2019 the top five countries for the cultivation of safflower, as cultivated areas, were: Kazakhstan, India, United States of America, Russian Federation and China, while, considering the total production, they were: Kazakhstan, United States of America, Mexico, India and Turkey. The countries with the best yields are Mexico, United States of America, China and Turkey. Among the European countries, Spain and Portugal lead the sector.

\subsection{Plant-Based By-Production}

Plant-based by-products include a wide range of residues generated by industrial processing of plants into commercially valuable products: these by-products can be used as animal feeds, helping in reduce the impact of the livestock production [11]. Among agriculture activities, the animal sector is responsible for almost two-thirds of the total GHG emissions [12]. It uses the $40 \%$ of the croplands for producing high-quality feeds [13], often in competition with food production. Feed production, transport, and utilisation play a major role in the environmental metrics of livestock production [11]. Although there is no consensus on the best strategy to reduce animal-based food use and impact, several authors suggested to integrate animal rearing in a circular paradigm, moving away from the current linear extractproduce-consume-discard model [3].

Plant-based by-products obtained from oilseed processing can be divided into two groups, depending on whether they are obtained before (shells, leaves, petals, stalks, pollen, heads and pith) or after (cake) the oil extraction process [14]. Some compounds from oilseed byproducts have an undesirable effect on the nutritional composition, by reducing the availability and digestibility of other constituents, or in the worst case affecting animal or human health; therefore, most part of the literature focuses on their dietary properties, neglecting to study the real possible reduction of the impact deriving from their use. Almeida 
Sá et al. [15] analyzed by-products from edible oil industries with high protein content, by a nutritional point of view. In their review, Yang et al. [16] include also the issue of the antinutritional ingredients. The literature about the impact or its reduction connected to the use of plant-based by-products for animal feeding is still limited. Salami et al. [11] produced a wide review of the effect of using different by-products by ruminants, examining the dualimpact of enteric methane and nitrogen emissions and meat quality. Schmidt [17] applied the life cycle analysis to five vegetable oils (palm, soybean, rapeseed, sunflower and peanut), including the effect of by-products in terms of GHG. To our knowledge, there is no study about the safflower and its by-product.

\section{MethodS}

This study was performed with the LCA methodology support as standardized procedure able to assess the environmental impacts of the proposed product system, including the specific unit processes in a cradle-to-gate approach. The reference ISO 14044:2006 Standards [18], [19] were considered.

SimaPro 9.0 software developed by Pré Consultants [20] and Ecoinvent 3.5 [21] supported the data processing for creating the LCA model and evaluating the overall environmental impact using IMPACT 2002+ method [22].

\subsection{Goal and Scope Definition}

The study's general objective is to evaluate the environmental impacts associated with the life cycle of safflower culture, from its cultivation until the final oil production. The study aims to assess the advantage and benefits related to the use of the oilcake as zootechnical feed. The geographical boundaries are set with reference to the middle Italy context.

According to the ISO Standards 14044, allocations have been avoided by extending the system boundaries to the use of the oilcake, to better evaluate the beneficial contribution coming from using by-products as a feed. In specific, the cake resulting from the safflower oil extraction, instead of being considered a waste, is used to produce zootechnical feed, assembling the cake with other ingredients. The use of the processing leftovers brings to an avoided environmental burden (Fig. 1). Normally, the zootechnical feed is composed of other raw materials like maize or fava bean.

\subsection{Functional Unit and System Boundaries}

The functional unit (FU) established for carrying out this study is 1 tonne of safflower oil; thus, all the inflows and outflows entering or leaving the system have been referred to this unit. The system boundaries referred to the FU are presented in Fig. 1. In the section of the inventory, the overall avoided impacts assumptions are described.

With reference to the scheme reported in Fig. 1, the overall investigated LCA system considers three mains unit processes: the safflowers cultivation and harvesting, the safflower oil extraction, and feed production starting from the cake. As previously mentioned, at this stage of the study the valorization of the by-product has been considered. 


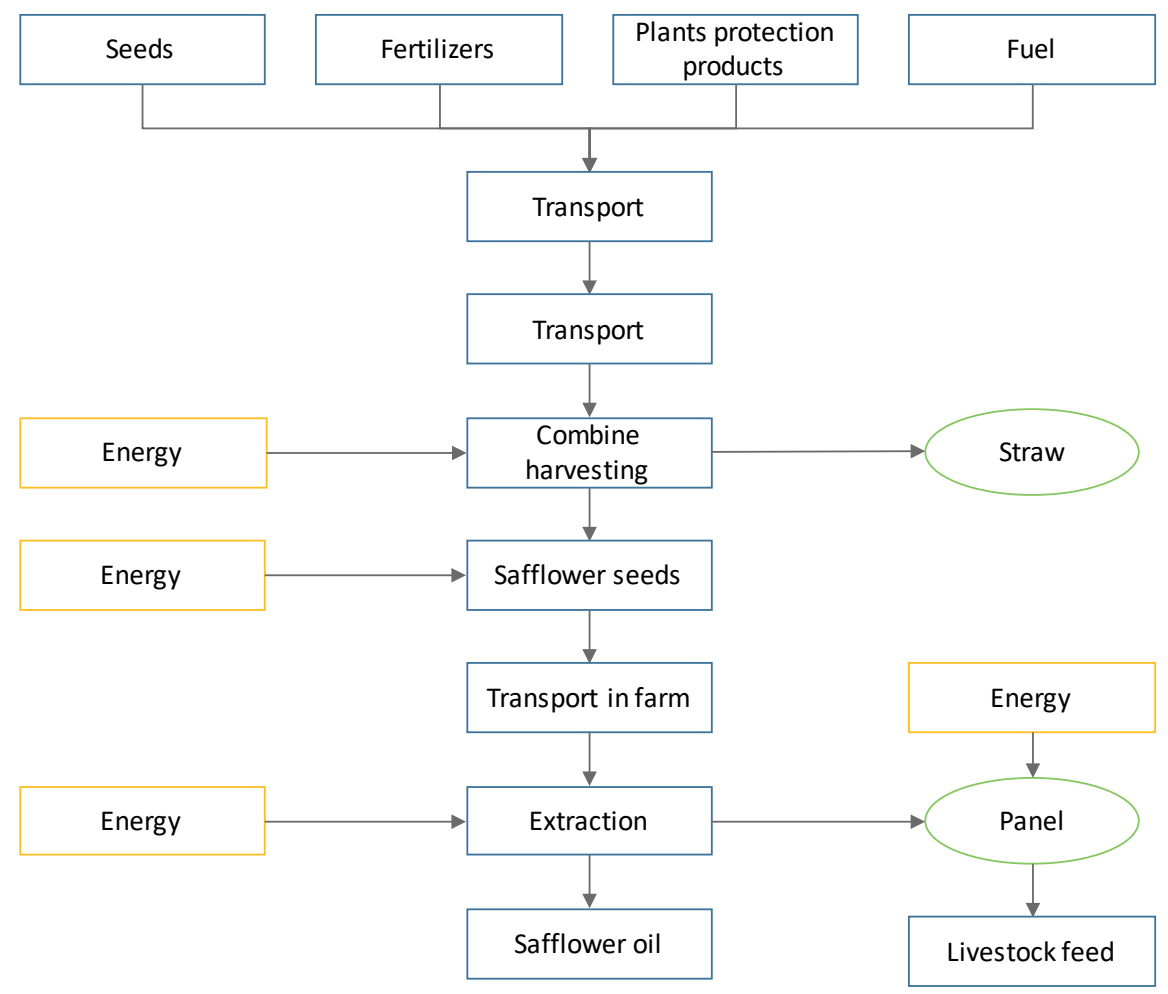

Fig. 1. System Boundaries of safflower oil production.

\subsection{Quality of the Input Data}

Primary data for food product in LCA studies is essential. The importance is even higher when dealing with the characterization of bio-based feedstock and their pathways. The reason mostly lies on the need to consistently include all upstream processes towards the whole value chain and the feedstock provision. Specifically, for the proposed study, the primary data source was based on the outcomes from the FORTE project [23], which could still provide a preliminary evaluation of all the specific aspects of safflower cultivation and harvesting.

FORTE project provides an interface for cooperation of several private companies and institutes focused on the practical implementation of bioeconomy principles and approaches for a sustainable creation of an agro-industrial chain in a middle Italy Region (i.e. Umbria). This framework provides the opportunity for synergistic use of agricultural resources and their co-products or side bio-waste stream from cultivation of low input oilseed. The aim is to set a consistent list of value-added products and their potential applications in different sectors.

From the FORTE project specific information were used in this study, mostly addressed to the background system. This information regards the safflower cultivation system up to the harvested biomass including biomass yields, seeding, ploughing, use of plant fertilizers and protection products, and agricultural operations for biomass movement and application of fertilizers and plant protection products. 
An Italian farm provided specific information for the data inventory of oil extraction while another important Italian feed-milling company provided the data for the production of feed from oilcake.

Ecoinvent 3.5 database [21] from Simapro software (C) was used as source for secondary data in terms of: transportation (i.e. distance and means of transport) and electricity supply system adapted to the Italian context.

\subsection{Impact Categories and Ipact Assessment Method}

For this specific case the selected Life Cycle Impact Assessment method was the end-point -based method IMPACT 2002+ for which final single score results can be presented with 4 main damage categories - i.e. Human Health, Biodiversity, Use of Resources, and Climate Change. The selection of this impact assessment method was mainly connected to have climate change as standing alone damage category.

IMPACT 2002+, acronym of IMPact Assessment of Chemical Toxics, was developed by Swiss Federal Institute of Technology - Lausanne (EPFL) [22]. In IMPACT2002+ midpoint impact category level consists of 15 environmental issues (midpoint indicators) namely: Human toxicity (carcinogens/non-carcinogens), Respiratory effects, Ionizing radiation, Ozone layer depletion, Photochemical oxidation, Aquatic and Terrestrial Ecotoxicity, Aquatic Acidification and Eutrophication, Terrestrial acidification, Land Occupation, Global warming, Non-renewable energy, Mineral Extraction.

\section{LIFE CyCLE INVENTORY ANALYSIS}

\subsection{The Production Process}

The first phase considered in the life cycle is the cultivation of safflower. After the annual process of cultivation, the grain is separated from the biomass, collected, and transported to the processing site where the second phase starts, i.e. the extraction of the oil and the recovery of the panel for zootechnical purposes.

In this second phase, the grain is cleaned, filtered and selected utilizing different sieves, of medium and small dimensions. Subsequently, oil is extracted from the safflower seeds. The oil extraction is mechanical, involving only electricity consumption and not implicating water or other raw materials.

After the extraction of the oil, the resulting seedcake is cleaned from impurities ready to enter into the production process of feed, which is destined to the poultry chain. The production of feed consists of the assembly of several raw materials, i.e. mainly safflower seedcake, soybean feed, maize grain feed, calcium carbonate, needing water and electricity consumption as primary inputs. In this case study, all the other feed components, except for the safflower seedcake, come from abroad.

\subsection{Data Assumptions and Data Sources}

Concerning the first phase of safflower cultivation, some Italian farms, located in the Umbria region and object of the present case study, provided all the main data. Marginal lands of Umbria region can easily be destined for this crop, thanks to its characteristics of resistance and adaptation to poor and arid soils. An important assumption must be reported concerning the land use. As marginal land use, otherwise not utilized for other purposes, the item "land use". was hypothesized not to be included for this type of cultivation. The reference cultivation area was one hectare. The yield of the crop is 1.3 ton/ha of grain. The main 
operations considered were ploughing, harrowing, sowing, fertilizing, mechanical weeding and harvesting. The fertilizers used during the cultivation were accounted as Urea, Diammonium Phosphate, and Potassium Chloride. The safflower seed was considered among the cultivation inputs available from the Ecoinvent database [15]. The transport processes of seeds and fertilizers were hypothesized with a distance from the storage point located in Umbria to the company warehouse supplier of $40 \mathrm{~km}$ and $10 \mathrm{~km}$ from the supplier to the farm.

Concerning emissions coming from the cultivation phase, nitrous oxide emissions were calculated using Global Nitrous Oxide Calculator [18]. GNOC is an online tool that returns the output data after entering information on: type of environment, agronomic management and geographical location. Within this study, Ammonia emissions were considered equal to $15 \%$ of the total nitrogen used [15], while $\mathrm{CO}_{2}$ emissions were considered equal to $20 \%$ of the total urea used [24], [25].

The data concerning the extraction stage comes from an Umbrian farm involved in this case study, which performed the transformation of seeds in oil within its own farm. Therefore, the inputs could vary within a wider industrial process. The distance from the site of cultivation to the site of transformation was $25 \mathrm{~km}$. In the extraction phase, the main inputs involved were safflower seeds and electricity. It is considered the extraction machine works $100 \mathrm{~kg}$ of seeds in 1 hour and consumes $5.5 \mathrm{kWh}$. The equivalent of 1 ton of extracted oil corresponds to $3.333 \mathrm{~kg}$ of seeds, with an oil yield of $23 \%$. No data on emissions were available for this process.

In relation to the third phase of feed production, the main inventory data were provided by Mignini\&Petrini spa, a big Italian company located in Umbria, producing feed, which was involved in the case study and in charge to test the safflower seedcake as an innovative ingredient within a typical feed designed for poultry. The other ingredients of the feed were maize from Romania, soybean cake and oil from Argentina. The necessary amounts of these ingredients for producing one ton of feed and related transport distances were accounted for. Other raw materials necessary for producing the feed were Calcium Carbonate coming from another Umbrian company, which was included in the analysis, Monocalcium Phosphate, Sodium chloride, Sodium bicarbonate and vitamins.

In addition to raw materials, the main inputs necessary for producing the feed were water and electricity. The necessary amount of water for 1 ton of feed was included in the process, considering that for $100 \mathrm{~kg}$ of feed 11.29 liters of water are needed. The electricity consumption $(4.5 \mathrm{kWh}$ for $100 \mathrm{~kg}$ ) was not included in the analysis, because the company Mignini\&Petrini spa produces electricity by itself, thanks to a cogeneration plant internal to the company. The emissions in air coming from this process consisted of few amounts of dust, while the emissions in water consisted of nitric nitrogen, chlorides and sulphates. No emissions in soil were present. A waste of $64 \mathrm{gr}$ for $100 \mathrm{~kg}$ of the product was considered.

Two by-products were produced during the life cycle analyzed: lignocellulosic biomass obtained from the cultivation phase, and seedcake obtained from the oil extraction phase. We assumed to avoid the allocation for this study, attributing all the environmental impact to the oil, as the seedcake would be considered a waste if not used for the feed. Therefore, the impact of safflower seedcake into the feed process is considered burden free. Moreover, the avoided environmental burden, connected with a standard feed production, was considered in the analysis.

The following table (Table 1) shows the main inputs for the evaluation of the overall environmental impact in terms of natural resources, materials, energy, waste-flows, and main emissions subdivided in each single unit process. 
TABLE 1. LCI WITH REFERENCE TO THE FU OF ONE TONNE OF SAFFlower PIL

\begin{tabular}{|c|c|c|c|}
\hline \multicolumn{4}{|l|}{ Cultivation Phase } \\
\hline Input & Unit & Amount & Data source/Comment \\
\hline Safflower seed & $\mathrm{kg} / \mathrm{ha}$ & 6 & \multirow{10}{*}{ Primary data from Umbrian local farms } \\
\hline Ploughing & ha & 1 & \\
\hline Harrowing & ha & 1 & \\
\hline Sowing & ha & 1 & \\
\hline Urea & $\mathrm{kg} / \mathrm{ha}$ & 120 & \\
\hline Diamonium phosphate & $\mathrm{kg} / \mathrm{ha}$ & 60 & \\
\hline Potassium Chloride & $\mathrm{kg} / \mathrm{ha}$ & 25 & \\
\hline Fertilizing & ha & 1 & \\
\hline Mechanical weeding & ha & 1 & \\
\hline Harvesting & ha & 1 & \\
\hline Transport of materials & $\mathrm{tkm}$ & 10.55 & $\begin{array}{l}\text { Hypothesis: } 40 \mathrm{~km} \text { from Umbrian storage to } \\
\text { supplier, } 10 \mathrm{~km} \text { from supplier to farm }\end{array}$ \\
\hline Output & Unit & Amount & Data source/Comment \\
\hline Achenes & ton & 1.3 & \multirow[t]{2}{*}{ Primary data from Umbrian company } \\
\hline Lignocellulosic Biomass & ton & 5.2 & \\
\hline Emissions & Unit & Amount & Data source/Comment \\
\hline $\mathrm{N}_{2} \mathrm{O}$ & $\mathrm{kg} / \mathrm{ha}$ & 1.18 & GNOC-JRC, 2014 [17] \\
\hline $\mathrm{NH}_{3}$ & $\mathrm{~kg} / \mathrm{ha}$ & 46.09 & Ecoinvent [14] \\
\hline $\mathrm{CO}_{2}$ & $\mathrm{~kg} / \mathrm{ha}$ & 61.46 & IPPC, $2006[18]$ \\
\hline \multicolumn{4}{|l|}{ Oil Extraction } \\
\hline Input & Unit & Amount & Data source/comment \\
\hline Seeds & $\mathrm{kg}$ & 3.33 & \multirow{2}{*}{ Primary data from Umbrian company } \\
\hline Electricity & MJ/ton extracted oil & 182.32 & \\
\hline Transport of seeds & $\mathrm{tkm}$ & 83.33 & Hypothesis: $25 \mathrm{~km}$ from farm \\
\hline Output & Unit & Amount & Data source/comment \\
\hline Extracted safflower oil & $\mathrm{kg}$ & 230 & \multirow{2}{*}{ Primary data from Umbrian company } \\
\hline Cake & $\mathrm{kg}$ & 757 & \\
\hline \multicolumn{4}{|l|}{ Feed Production } \\
\hline Input & Unit & Amount & Data source/comment \\
\hline Safflower cake & ton & 0.15 & \multirow{6}{*}{ Mignini \& Petrini spa company } \\
\hline Maize grain feed & ton & 0.41 & \\
\hline Soybean feed & ton & 0.21 & \\
\hline Carbonate calcium & ton & 0.01 & \\
\hline Water & $\mathrm{m}^{3}$ & 112.9 & \\
\hline Transport & $\mathrm{tkm}$ & 6127.3 & \\
\hline Output & Unit & Amount & Data source/comment \\
\hline Feed & ton & 1 & \\
\hline Emission in air & Unit & Amount & Data source/comment \\
\hline Dust & $\mathrm{g} / 100 \mathrm{~kg}$ & 6 & \\
\hline $\begin{array}{l}\text { Nitric nitrogen, Chlorides, } \\
\text { Sulphates }\end{array}$ & $\mathrm{g} / 100 \mathrm{~kg}$ & 1.5 & \\
\hline Waste & $\mathrm{g} / 100 \mathrm{~kg}$ & 64 & \\
\hline
\end{tabular}




\section{Results}

\subsection{Environmental Impact of the Base Line Scenario}

In this paragraph the main results using the Impact 2002 method are reported [22].

Fig. 2 shows the environmental impact of the components of the safflower oil production cycle (normalized values). Results show that the most significant impact is due to the crop fertilisation, followed by operations of tillage and harvesting; on the other hand, the oil extraction has a negligible effect. This evidence implies that the cultivation phase results more impacting than the transformation from crop to oil., due to the higher use of chemical inputs and operations and produces more air emissions. The most impactful categories were Respiratory inorganics, followed by Global warming and Non-renewable energy, for what concerns the mid-point categories (Fig. 2). Consequently, Human Health, Resources and Climate Change were the most end-point categories involved (Fig. 3). The results of the normalization determine that the category of damage with the far greater value is 'Human Health'.

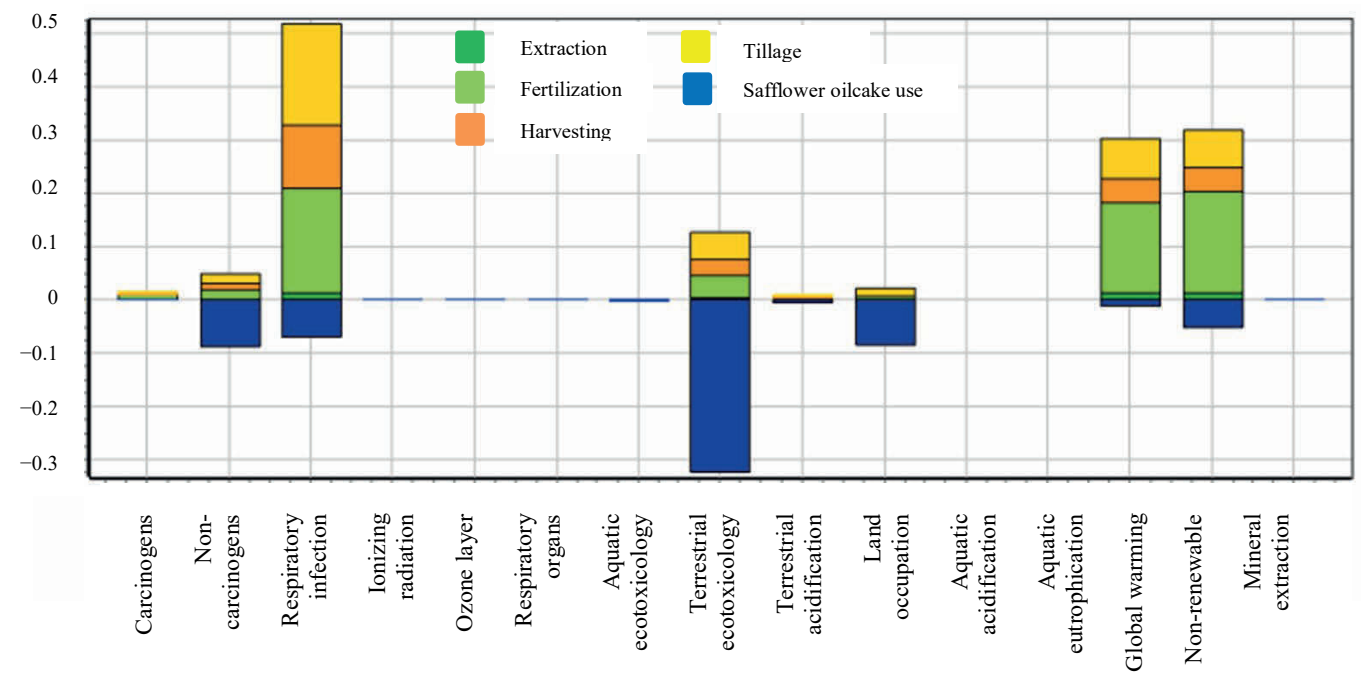

Fig. 2. Environmental impact of the various components of the production cycle of safflower oil referring to one ton of oil produced; normalization phase, mid-point categories.

Figs. 2 and 3 also show the results of cake employment in the feed production, highlighting the avoided environmental burden connected with standard feed production. In fact, the safflower cake was used to formulate a zootechnical feed, as it has a high protein content, instead of by-products coming from the extraction of sunflower oil which, given the low cost, are generally imported from abroad.

The use of the panel for feed production generated an environmental advantage for various categories, particularly Terrestrial ecotoxicity. The avoided production of standard feed generated an avoided impact for the damage categories, especially in the Ecosystem quality category.

This aspect is due to the avoided production of the standard feed, which uses imported products mostly in terms of greater use of maize, always imported, used to balance the feed nutritional level. 
From the results obtained we can assume that the cultivation of safflower is a valid option for the use of marginal soils in the Umbrian territory, which otherwise would not be exploited since their characteristics would not allow the optimal growth of other cultivars less adaptable to this type of land.

This result could represent a starting point for creating an entirely national supply chain to lead to a more substantial reduction of the impacts. Additionally, the use of marginal local lands and avoiding exporting raw material from abroad could help develop a more sustainable feed supply chain.

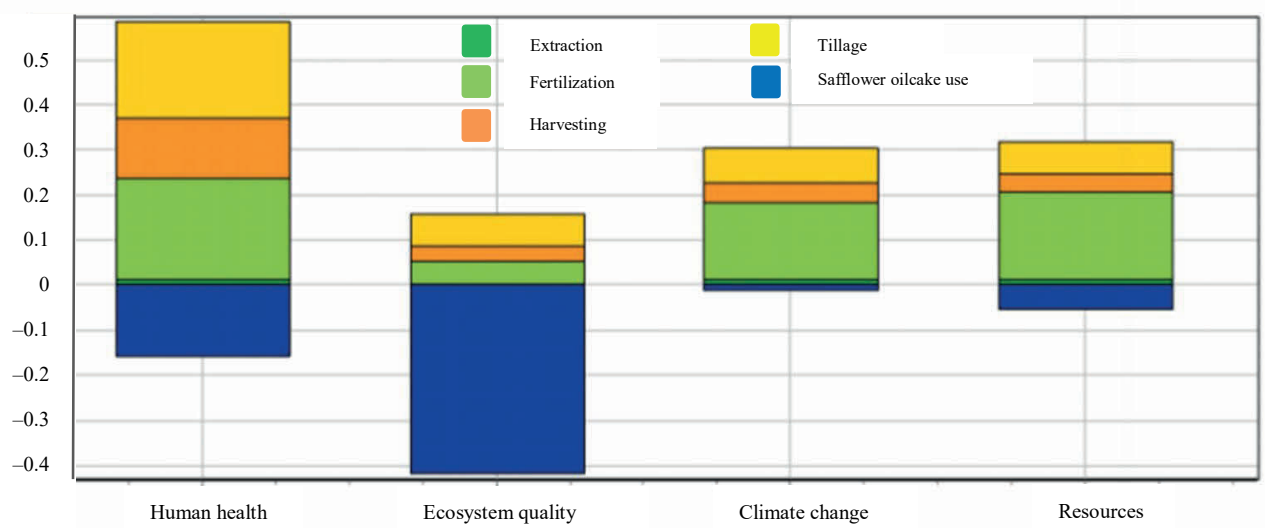

Fig. 3. Environmental impact of the various components of the production cycle of safflower oil referring to one ton of oil produced; normalization phase, end-point categories.

\subsection{Sensitivity Analysis}

The authors conducted a sensitivity analysis on the crop yield. This parameter selection was due to its high variability depending on the type of soil, the climatic trend, and the soil water availability. Like all agricultural productions, the production yield is also poorly controllable by the farmer. This consideration regarding production variability is particularly appropriate in the case study, given that cultivation has been carried out in marginal fields, which already present sub-optimal characteristics.

Four yield variations thresholds have been considered: $+20 \%,+10 \%,-10 \%,-20 \%$. This choice was based on the yield data of the cultivation for different companies and in different years.

TABLE 2. SENSITIVITY ANALYSIS

\begin{tabular}{ccc}
\hline Yield variation, \% & Ecopoint variation, \% & Sensitivity ratio \\
\hline-20 & +31.49 & 1.57 \\
-10 & +20.58 & 2.06 \\
+10 & -16.30 & 1.63 \\
+20 & -29.70 & 1.49 \\
\hline
\end{tabular}

The analysis showed that with any change in yield, the final result in terms of impact increases or decreases more than proportional to the variation that generated it. However, contractions of production cause a more significant variation than the increase in production. 
The most significant result is obtained with a $10 \%$ yield reduction, which brings the sensitivity ratio (i.e. Ecopoint variation [\%]/Yield variation [\%]) to 2.06. A higher yield reduction $(-20 \%)$, on the other hand, generates a sensitivity ratio greater than 1 , but lower than the value identified for the yield level $-10 \%$.

\section{Conclusions}

This work represents a practical application of circular economy and bioeconomy principles to the Umbrian agricultural territory, in particular by optimizing the implementation of oilseed crops chains for industrial use. This first environmental analysis of the production cycle represents one of the initial phases for achieving the objective mentioned above. At the same time, the need for a further development would also be connected with interest that farms show towards environmental issues.

As concerning oil production, the fertilization phase resulted being the most impacting process. To further reduce this process impact, fertilizations with crop residues or other waste products from other crops could be carried out.

In relation to feed production, results showed that the environmental gain obtained is very significant. This data could be taken as a starting point for creating a supply chain constructed entirely at a national level, to arrive at a more substantial reduction of impacts.

Finally, the sensitivity analysis showed how the cultivar yield is a very important value concerning the final results obtained. Attention must be paid to the cultivation phase, reducing damage to the crop as much as possible and implementing optimal cultivation strategies.

This study could be useful for farms, which can optimize and transform their marginal space, currently uncultivated or not very productive, into new areas of productivity. This aspect could provide lymph to the local economy and exploit cultivation that had been abandoned in the past. In this way, this mechanism could lead to producing quality oil and at the same time contributing in optimizing the effect of the circular economy, using all parts of the safflower, even those that previously would have been labelled as waste.

\section{ACKNOWLEDGEMENT}

This study was partly funded by the FORTE project (2014-2020 Umbrian Rural Development Programme- sub-measure 16.1), co-funded by the European Agricultural Fund for Rural Development (EAFRD) and by the Fondo di Ricerca di Base di Ateneo-2019.

\section{REFERENCES}

[1] Lucchetti M. G., et al. The Role of Environmental Evaluation within Circular Economy: An Application of Life Cycle Assessment (LCA) Method in the Detergents Sector. Environmental and Climate Technologies 2019:23:238-257. https://doi.org/10.2478/rtuect-2019-0066

[2] Ghisellini P., Cialani C., Ulgiati S. A review on circular economy: the expected transition to a balanced interplay of environmental and economic systems. Journal of Cleaner Production 2016:114:11-32. https://doi.org/10.1016/i.jclepro.2015.09.007

[3] Van Zaten H. H. E., Van Ittersum M. K., DeBoer I. J. M. The role of farm animals in a circular food system. Global Food Security 2019:21:18-22. https://doi.org/10.1016/j.gfs.2019.06.003

[4] Mateos-Aparicio I. Chapter 19 - Plant-based by-products. Food Waste Recovery. Academic Press, 2021:367-397. https://doi.org/10.1016/B978-0-12-820563-1.00022-6

[5] Hussain M. I., et al. Salt and drought stresses in safflower: a review. Agronomy for Sustainable Development 2016:36:4. https://doi.org/10.1007/s13593-015-0344-8 
[6] Yesilyurt M. K., et al. The production of biodiesel from safflower (Carthamus tinctorius L.) oil as a potential feedstock and its usage in compression ignition engine: A comprehensive review. Renewable and Sustainable Energy Reviews 2020:119:109574. https://doi.org/10.1016/j.rser.2019.109574

[7] Smith J. R. Saffower. AOCS press: Champaing, 1991.

[8] GRDC. Raising the bar with better safflower agronomy - Autumn 2010. Agronomic information and safflower case studies. Barton: GRDC, 2010.

[9] Oelke E. A., et al. Safflower. Alternative Field Crop Manual. Madison: University of Wisconsin-Extension, Cooperative Extension, 1992.

[10] FAO stat, Statistics [Online]. [Accessed 29.01.2020]. Available: http://www.fao.org/faostat/en/\#data/QC/visualize

[11] Salami S. A., et al. Sustainability of feeding plant by-products: A review of the implications for ruminant meat production. Animal Feed Science and Technology 2019:251:37-55. https://doi.org/10.1016/j.anifeedsci.2019.02.006

[12] Poore J., Nemecek T. Reducing food's environmental impacts through producer and consumers. Science 2018:360(6392):987-992. https://doi.org/10.1126/science.aaq0216

[13] Mottet A., et al. Livestock: on our plates or eating at our table? A new analysis of the feed/food debate. Global Food Security 2017:14:1-8. https://doi.org/10.1016/j.gfs.2017.01.001

[14] Rodríguez-Roque M.j., et al. By-Products from Oilseed Processing and Their Potential Applications. Oil and Oilseed Processing: Opportunities and Challenges. Hoboken: Hohn Wiley\&Sons, 2021. https://doi.org/10.1002/9781119575313.ch9

[15] Almeida Sá A. G., et al. Oilseed by-products as plant-based protein sources: Amino acid profile and digestibility. Future Foods 2021:3:100023. https://doi.org/10.1016/j.fufo.2021.100023

[16] Yang K., et al. By-Product Feeds: Current Understanding and Future Perspectives. Agriculture 2021:11(3):207. https://doi.org/10.3390/agriculture11030207

[17] Schmidt J. K. Life cycle assessment of five vegetable oils. Journal of Cleaner Production 2015:87:130-138. https://doi.org/10.1016/j.jclepro.2014.10.011

[18] ISO 14044: Environmental Management-Life Cycle Assessment-Requirements and Guidelines. ed. vol.: ISO. 2006.

[19] ISO 14040: Environmental management-Life cycle assessment-Principles and framework. ed. vol.: ISO. 2006

[20] Goedkoop M., et al. Introduction to LCA with SimaPro. San Francisco: Pre, 2016.

[21] Wernet G., et al. The database version 3 (part I): overview and methodology. The International Journal of Life Cycle Assessment 2016:21(9):1218-1230. https://doi.org/10.1007/s11367-016-1087-8

[22] Jolliet O., et al. IMPACT 2002+: A new life cycle impact assessment methodology. The International Journal of Life Cycle Assessment 2003:8:324. https://doi.org/10.1007/BF02978505

[23] FORTE project. Filiera delle Oleaginose a Recupero Total (Total recovery oilseed chain) [Online]. [Accessed: 06.11.2020]. Available: https://www.goforte.it/ (in Italian)

[24] Köble R. JRC Technical Reports. The Global Nitrous Oxide Calculator - GNOC - Online Tool Manual. Version 1.2.4. Brussels: Publications Office of the European, 2013.

[25] IPCC. Guidelines for National Greenhouse Gas Inventories. Geneva: IPCC, 2006. 